\title{
Transplantation of adipose derived stem cells overexpressing inducible nitric oxide synthase ameliorates diabetes mellitus induced erectile dysfunction in rats
}

\author{
Yan Zhang ${ }^{1,2}$, Jun Yang ${ }^{1,2}$, Li Zhuan ${ }^{3}$, Guanghui Zang ${ }^{4}$, Tao Wang ${ }^{1,2}$, Jihong Liu ${ }^{\text {Corresp. } 1,2}$ \\ ${ }^{1}$ Department of Urology, Tongji Hospital, Tongji Medical College, Huazhong University of Science and Technology, Wuhan, Hubei, China \\ 2 Institute of Urology, Tongji Hospital, Tongji Medical College, Huazhong University of Science and Technology, Wuhan, Hubei, China \\ 3 Department of Reproductive Medicine, the First People's Hospital of Yunnan Province, Kunming, Yunnan, China \\ 4 Department of Urology, Xuzhou City Centre Hospital, Xuzhou, Jiangsu, China \\ Corresponding Author: Jihong Liu \\ Email address: jhliu@tjh.tjmu.edu.cn
}

Background: Erectile dysfunction is a major complication of diabetes mellitus. Adipose derived stem cells (ADSCs) have attracted much attention as a promising tool for the treatment of diabetes mellitus induced erectile dysfunction (DMED). Inducible nitric oxide synthase (iNOS) plays an important role in protecting penile tissues from fibrosis. The aim of this study was to determine the efficacy of ADSCS overexpressing iNOS on DMED in rats.

Methods: ADSCs were isolated and infected with adenovirus overexpressing iNOS (named as ADSCSiNOS). The expression of iNOS was detected using western blot analysis and real-time PCR. Rats were randomly assigned into five groups: control group, DMED group, ADSCs group, ADSCs-EGFP group and ADSCs-iNOS group. $5 \times 10^{5}$ cells were given once via the intracorporal route. Two weeks after treatment, erectile function was assessed by electrical stimulation of the cavernous nerve. Penile tissues were obtained and evaluated at histology level.

Results: We found that ADSCs-iNOS had significantly higher expression of iNOS at mRNA and protein levels and generated more nitric oxide. ADSCs-iNOS reduced collagen I and collagen IV expression of corpus cavernosum smooth muscle cells (CCSMCs) in cell co-culture model. Transforming growth factor$\beta 1$ expression in CCSMCs reduced following co-culture with ADSCs-iNOS. Injection of ADSCs-iNOS significantly ameliorated DMED in rats and decreased collagen/smooth muscle cell ratio of penile tissues. Moreover, elevated nitric oxide and cGMP concentrations were detected in penile tissues of ADSCs-iNOS group.

Conclusion: Taken together, ADSCs-iNOS significantly improved erectile function of DMED rats. The therapeutic effect may be achieved by increased nitric oxide generation and the suppression of collagen I and collagen IV expression in the CCSMCs to decrease penile fibrosis. 


\section{Transplantation of adipose derived stem cells}

\section{2 overexpressing inducible nitric oxide synthase}

3 ameliorates diabetes mellitus induced erectile

4 dysfunction in rats

5

6

7

8

9

10

11
Yan Zhang ${ }^{1,2}$, Jun Yang ${ }^{1,2}$, Li Zhuan ${ }^{3}$, Guanghui Zang ${ }^{4}$, Tao Wang ${ }^{1,2}$, Jihong Liu ${ }^{1,2}$

${ }^{1}$ Department of Urology, Tongji Hospital, Tongji Medical College, Huazhong University of Science and Technology, Wuhan, Hubei, China.

${ }^{2}$ Institute of Urology, Tongji Hospital, Tongji Medical College, Huazhong University of Science and Technology, Wuhan, Hubei, China.

${ }^{3}$ Department of Reproductive Medicine, the First People's Hospital of Yunnan Province, Kunming, Yunnan, China.

${ }^{4}$ Department of Urology, Xuzhou City Centre Hospital, Xuzhou, Jiangsu, China

Corresponding Authors:

Jihong Liu

Department of Urology, Tongji Hospital, 1095 Jiefang Avenue, Wuhan, 430030, Hubei, China. E-mail address: jhliu@tjh.tjmu.edu.cn. 


\section{Abstract}

Background: Erectile dysfunction is a major complication of diabetes mellitus. Adipose derived stem cells (ADSCs) have attracted much attention as a promising tool for the treatment of diabetes mellitus induced erectile dysfunction (DMED). Inducible nitric oxide synthase (iNOS) plays an important role in protecting penile tissues from fibrosis. The aim of this study was to determine the efficacy of ADSCs overexpressing iNOS on DMED in rats.

Methods: ADSCs were isolated and infected with adenovirus overexpressing iNOS (named as ADSCs-iNOS). The expression of iNOS was detected using western blot analysis and real-time PCR. Rats were randomly assigned into five groups: control group, DMED group, ADSCs group, ADSCs-EGFP group and ADSCs-iNOS group. $5 \times 10^{5}$ cells were given once via the intracorporal route. Two weeks after treatment, erectile function was assessed by electrical stimulation of the cavernous nerve. Penile tissues were obtained and evaluated at histology level.

Results: We found that ADSCs-iNOS had significantly higher expression of iNOS at mRNA and protein levels and generated more nitric oxide. ADSCs-iNOS reduced collagen I and collagen IV expression of corpus cavernosum smooth muscle cells (CCSMCs) in cell co-culture model. Transforming growth factor- $\beta 1$ expression in CCSMCs reduced following co-culture with ADSCs-iNOS. Injection of ADSCs-iNOS significantly ameliorated DMED in rats and decreased collagen/smooth muscle cell ratio of penile tissues. Moreover, elevated nitric oxide and cGMP concentrations were detected in penile tissues of ADSCs-iNOS group.

Conclusion: Taken together, ADSCs-iNOS significantly improved erectile function of DMED rats. The therapeutic effect may be achieved by increased nitric oxide generation and the suppression of collagen I and collagen IV expression in the CCSMCs to decrease penile fibrosis.

\section{Introduction}

Erectile dysfunction (ED) is one of the most significant complications in men with diabetes mellitus (DM). Numerous studies have found that more than $50 \%$ of men with DM are afflicted with ED (Thorve et al., 2011). Men with DM tend to suffer from ED about 10 years earlier than the general population (Johannes et al., 2000). Diabetes mellitus induced erectile dysfunction (DMED) is severe and has a negative effect on the quality of life. Phosphodiesterase 5 inhibitors are the predominant medicines to treat ED. However, diabetic male patients are less responsive to phosphodiesterase 5 inhibitors (Cheng, 2007). Therefore, developing new therapeutic options for DMED is urgent.

Over the past years, stem cell therapy has produced positive effects on DMED in experimental animals. Adipose derived stem cells (ADSCs) are attracting considerable attention becuase they can be isolated through standardized procedures and vastly expanded, and they secrete a broad range of trophic factors (Sowa et al., 2012). Moreover, ADSC transplantation seems to be safe and avoid the risks of tumorigenesis (Alagesan \& Griffin, 2014). Autologous ADSCs significantly improved erectile function of type-II diabetic rats (Garcia et al., 2010). 
Stem cell therapy has beneficial effects to increase smooth muscle and endothelium, NO-cGMP pathway, neuronal nitric oxide synthase (nNOS)-positive nerve fibers, and decrease fibrosis and apoptosis in the penis (Chen et al., 2017; Qiu et al., 2011; Ryu et al., 2012; Sun et al., 2012; Zhang et al., 2016).

Nitric oxide (NO) is a neurotransmitter which plays an important role in penile erection. NO is synthesized by three nitric oxide synthase (NOS) isoforms, including nNOS, endothelial NOS (eNOS) and inducible NOS (iNOS). Among these synthases, iNOS can produce NO continuously independent of $\mathrm{Ca}^{2+}$ (Eissa et al., 1998). Recent evidence suggests that the pathogenesis of DMED may be due to impaired NO production, and iNOS acts an essential part in protecting penile tissues from the pro-fibrotic effects of hyperglycemia (Ferrini et al., 2010). Continuous NO production by iNOS inhibits collagen synthesis, directly reacts with ROS to produce peroxynitrite, and downregulates transforming growth factor- $\beta 1$ (TGF- $\beta 1$ )/Smad pathway, thus reducing fibrosis level (Gonzalez-Cadavid \& Rajfer, 2010). Gene transfer of iNOS DNA decreased TGF- $\beta 1$ and plasminogen-activator inhibitor-1 expression, and regressed Peyronie's disease-like plaque (Davila et al., 2004). Our previous study showed that saRNA mediated iNOS expression improved DMED via endogenously generating NO (Wang et al., 2013).

Given the beneficial effects of ADSCs and iNOS in the treatment of ED, we hypothesized that ADSCs combined with iNOS could improve erectile function of DMED rats. In this study we aimed to determine the efficacy of ADSCs combined with iNOS for improving erectile function in DMED rats.

\section{Materials and methods}

\section{Rat ADSCs isolation and culture}

Rat ADSCs were isolated as previously described (Wang et al., 2015). Briefly, adipose tissues were incised from inguen, and digested at $37^{\circ} \mathrm{C}$ in $0.1 \%$ collagenase type I (SigmaAldrich, St. Louis, USA) with vigorous shaking for 90 minutes. The digested tissues were mixed with Dulbecco's modified Eagle's medium (DMEM) supplemented with 10\% fetal bovine serum (FBS), and centrifuged at $220 \mathrm{~g}$ for 10 minutes. The cells were suspended in DMEM containing $10 \%$ FBS and filtered through a $75-\mu \mathrm{m}$ cell striner (Solarbio, Beijing, China). Then cells were plated and cultured in DMEM containing $10 \% \mathrm{FBS}$ at $37^{\circ} \mathrm{C}$ in humidified incubator with $5 \%$ $\mathrm{CO}_{2}$. Cells were passaged with trypsin/EDTA (Beyotime, Nantong, China) as required. The fourth-passage ADSCs were used in this study.

\section{Flow cytometry}

ADSCs were characterized by flow cytometry at passage 4. Briefly, ADSCs were harvested and washed twice with phosphate-buffered saline (PBS). Then, the cells were incubated for 30 minutes in PBS containing anti-CD29-FITC(cat. \# 555005, BD, San Diego, USA), CD31-PE(cat. \# 555027, BD), CD49-FITC(cat. \# 557457, BD), CD90-PE(cat. \# 551401, BD), CD106-PE(cat. \# 559229, BD), CD34-FITC(cat. \# sc-7324, Santa Cruz, Dallas, Texas), CD45-FITC(cat. \# 
MCA43FT, AbD, Oxford, UK), CD73-FITC (cat. \# bs-23233R, Bioss, Beijing, China), CD105FITC (cat. \# bs-10662R, Bioss). The stained cells were then subjected to flow cytometry analysis.

\section{Differentiation of ADSCs}

For adipocyte differentiation, ADSCs were cultured at a density of $1 \times 10^{4} \mathrm{cells} / \mathrm{cm}^{2}$ in DMEM containing $10 \% \mathrm{FBS}, 50 \mathrm{mg} / \mathrm{L}$ indomethacin, $0.5 \mathrm{mmol} / \mathrm{L}$ isobutylmethylxanthine, 10 $\mathrm{mg} / \mathrm{L}$ insulin and $1 \mathrm{mmol} / \mathrm{L}$ dexamethasone (all from Sigma-Aldrich). After 21 days of induction, the cells were stained using Oil red-O staining solution.

For smooth muscle cell differentiation, ADSCs were cultured at a density of $1 \times 10^{4} \mathrm{cells} / \mathrm{cm}^{2}$ in low-glucose DMEM containing $10 \% \mathrm{FBS}, 50 \mu \mathrm{g} / \mathrm{mL}$ platelet-derived growth factor-BB and 5 $\mu \mathrm{g} / \mathrm{L}$ TGF- $\beta 1$ (all from PeproTech, Rocky Hill, USA). After 14 days of induction, the cells were stained with the antibody against $\alpha$-smooth muscle actin ( $\alpha$-SMA, cat. \# BM0002, Boster, Wuhan, China). Immunofluorescence staining was performed as previously described (Zhang et al., 2016).

\section{Transfection with adenovirus}

The fourth-passage ADSCs were cultured for $24 \mathrm{~h}$. ADSCs were incubated with adenovirus expressing EGFP or iNOS-EGFP (GenecChem, Shanghai, China) at a multiplicity of infection (MOI) of 30. After incubation for $12 \mathrm{~h}$, the medium was changed into fresh growth medium.

\section{Real-time PCR}

Real-time PCR was performed in cultured cells on the 1st, 3rd, 5th, 7th, 10th and 14th day after infection with adenovirus. RNA was extracted with a multisource RNA miniprep kit (Corning, NY, USA). Total RNA (500 ng) was reversely transcribed into cDNA using the PrimeScript $^{\mathrm{TM}}$ RT reagent kit (TaKaRa, Dalian, China). Real-time PCR for each sample was performed on an MX3000P quantitative PCR system (Agilent, Santa Clara, USA) using SYBR Premix Ex Taq (TaKaRa) and the following primers: iNOS 5'AaGCACATTTGGCAATGGAGAC-3', 5'-TGGAGCCCAGGCCAAATAC-3', $\beta$-actin _ 5'GACGGTGTGCACCAACATCTA-3', 5'-TTCTTGGCTTTCAGGATGGAG-3'. PCR condition included $95^{\circ} \mathrm{C}$ for 30 seconds, followed by 40 cycles of $95^{\circ} \mathrm{C}$ for 5 seconds, $60^{\circ} \mathrm{C}$ for 30 seconds and $72^{\circ} \mathrm{C}$ for 30 seconds. Relative expression level of target genes was calculated with $2^{-\Delta \Delta \mathrm{Ct}}$ method. $\beta$-actin was chosen as normalization control.

\section{Western blot analysis}

Protein extraction from rat penile tissues and cultured cells was performed using NP-40 lysis buffer (Beyotime). Protein concentration was detected with the BCA protein assay kit (Beyotime). $50 \mu \mathrm{g}$ protein was electrophoresed on $12 \%$ sodium dodecyl sulfate/polyacrylamide gels and then blotted on a polyvinylidene difluoride membrane (Millipore, Billerica, USA). The membrane was blotted with primary antibodies against collagen I (cat. \# 14695-1-AP, Proteintech, Wuhan, China), collagen IV (cat. \# 55131-1-AP, Proteintech), iNOS (cat. \# sc-7271, Santa Cruz, Dallas, USA), TGF- $\beta 1$ (cat. \# ab92486, Abcam, Cambridge, UK)) followed by 
141 HRP-labelled secondary antibodies. The enhanced chemiluminescence detection system (Pierce; 142 Thermo Fisher, Rockford, USA) was used to detect protein bands. Each band was quantified by densitometry with Image J software.

\section{Measurement of NO concentration}

Cells were incubated in culture medium containing $10 \mathrm{mmol} / \mathrm{L} \mathrm{L}$-Arginine for $24 \mathrm{~h}$ on the $1 \mathrm{st}$, 3rd, 5th, 7th, 10th and 14th day after infection with adenovirus. Then the supernatant was harvested. NO concentrations in penile tissues or cultured cells were determined with total NO assay kit (Beyotime) according to the manufacturer's instructions.

\section{Cyclic guanosine monophosphate (cGMP) concentration determination}

The cGMP concentrations in penile tissues or cultured cells were measured using an enzymelinked immunosorbent assay (ELISA) kit (Westang, Shanghai, China) according to the manufacturer's instructions.

\section{Rat corpus cavernosum smooth muscle cell (CCSMC) isolation and culture}

Rat CCSMCs were obtained from corpus cavernosum tissues as described previously with minor modifications(Chen et al., 2011). Briefly, corpus cavernosum tissues were harvested and cut into fragments of $1 \mathrm{~mm}^{3}$. These fragments were placed in an overturned $25 \mathrm{~cm}^{2}$ culture flask. Then, $4 \mathrm{ml}$ DMEM containing 10\% FBS was added into culture flask. After 30 minutes, the flask was flipped over. Differential adherence method was used to purify CCSMCs. Immunostaining with an antibody against $\alpha$-SMA was performed to identify CCSMCs. Immunofluorescence staining was performed as previously described (Zhang et al., 2016).

\section{Transwell co-culture of ADSCs and CCSMCs}

ADSCs and CCSMCs were co-cultured in medium containing $30 \mathrm{mmol} / \mathrm{L}$ glucose in $0.4 \mu \mathrm{m}$ pore size Transwell inserts (Corning, NY, USA). CCSMCs were cultured in 12-well plates at $1 \times 10^{4}$ cells/well. ADSCs, ADSCs-EGFP or ADSCs-iNOS were seeded on Transwell inner membrane at a density of $1 \times 10^{4}$ cells/well. The co-culture system allowed ADSCs and CCSMCs to grow in the same medium without direct contact between them.

\section{Animal experiments}

Animal experiments were carried out according to the guidelines and regulations by the Ethical Committee of Tongji Hospital, Tongji Medical College, Huazhong University of Science and Technology. This study was approved by the Ethical Committee (TJ-A20131213). Sixty male SD rats (8-week old) were purchased from Hunan SJA Laboratory Animal Co., Ltd. After an overnight fast, fifty-one of them were randomly selected and received intraperitoneal injection with streptozotocin (60 mg/kg, Sigma-Aldrich) (Yang et al., 2013). The remaining 9 rats were used as controls. Three days after streptozotocin injection, rats with fasting blood glucose level higher than $16.7 \mathrm{mmol} / \mathrm{L}$ were selected as DM. After 8 weeks, DM rats were selected by the apomorphine (APO) test. Briefly, APO (80 mg/kg, Sigma-Aldrich) was injected in the loose skin 
182

183

184

185

186

187

188

189

190

191

192

193

194

195

196

197

198

199

200

201

202

203

204

205

206

207

208

209

210

211

212

213

214

215

216

217

218

219

220

221

of neck. DMED rats were identified if rats did not exhibit an erectile response within 30 minutes.

DMED rats were randomly divided into different treatment groups ( 9 rats in each group): DMED group received no treatment; ADSCs group received corpus cavernosum injection of 60 $\mu \mathrm{l}$ PBS containing $5 \times 10^{5}$ ADSCs; ADSCs-EGFP group received corpus cavernosum injection of $60 \mu \mathrm{PBS}$ containing $5 \times 10^{5}$ ADSCs-EGFP; ADSCs-iNOS group received corpus cavernosum injection of $60 \mu \mathrm{l}$ PBS containing $5 \times 10^{5}$ ADSCs-iNOS.

\section{Assessment of erectile function}

After 2 weeks, intracavernous pressure (ICP) and mean arterial pressure (MAP) were detected to evaluate erectile function as described previously (Yang et al., 2013). The stimulus parameters were two voltages $(2.5,5.0$ volts), frequency $15 \mathrm{~Hz}$, duration 1 minute and pulse width $1.2 \mathrm{~ms}$. Erectile response was measured at 2.5 and 5.0 voltages. Pressure was measured and recorded with a data acquisition system (AD Instruments Powerlab/4SP, NSW, Australia). Then, penile tissues were harvested for measurement of NO and cGMP concentration $(\mathrm{n}=$ 4 /group) and masson trichrome staining $(n=5 /$ group $)$

\section{Masson trichrome staining}

Penile tissues were embedded in paraffin and cut into $5 \mu \mathrm{m}$ thick sections. Masson trichrome staining was performed as previously described (Yang et al., 2013). Image Pro Plus 6.0 software (Media Cybernetics Inc, Bethesda, USA) was used to quantitatively analyze smooth muscle content and collagen in five randomly selected specimens per group.

\section{Statistical Analysis}

Results were expressed as mean \pm standard deviation. Data were analyzed with one-way analysis of variance followed by Tukey-Kramer test for post hoc comparisons using GraphPad Prism 5.0 (GraphPad Software, San Diego, USA). Normal distribution was determined by Kolmogorov-Smirnov test. $P<0.05$ was considered statistically significant.

\section{Results}

\section{Isolation and characterization of ADSCs}

The isolated ADSCs exhibited spindle-shaped morphology at passage 1 (Fig. 1A). ADSCs expanded in vitro and showed fibroblast-like shape at passage 4 (Fig. 1B). To characterize ADSCs, surface markers of the cultured cells at passage 4 were determined using flow cytometry. As shown in Fig. 1C-K, most of the cells expressed CD29 and CD90, while few cells were positive for CD34, CD45, CD73, CD105, CD31 and CD106. To identify the multi-lineage differentiation ability of ADSCs, we induced adipogenic and myogenic differentiation of ADSCs for 21 or 14 days in appropriate induction medium. Oil red-O staining indicated that ADSCs could differentiate to adipocytes (Fig. 1L). Immunofluorescence staining with an antibody against $\alpha$-SMA indicated that ADSCs could differentiate to smooth muscle cells (Fig. 1M).

After culture for 5 to 7 days primary rat CCSMCs in spindle shape grew out of corpus 
222 cavernosum tissues. After about 2 weeks of culture, cells were passaged and purified by the

223

224

225

226

227

228

229

230

231

232

233

234

235

236

237

238

239

240

241

242

243

244

245

246

247

248

249

250

251

252

253

254

255

256

257

258

259

260

261

262

differential adherence method (Fig. 1N). The cells were identified as CCSMCs by immunostaining of $\alpha$-SMA (Fig. 1O).

\section{Overexpression of iNOS in ADSCs}

To overexpress iNOS in ADSCs, we infected the cells with recombinant adenovirus. 3 days after infection, fluorescence microscopy was used to observe EGFP-expressing ADSCs (Fig. 2AC). Real-time PCR and Western blot analysis showed that the mRNA and protein expression levels of iNOS were significantly higher in ADSCs-iNOS group than ADSCs-EGFP and ADSCs groups $(P<0.05$, Fig. 2D and 2E). The expression of iNOS in ADSCs could persisted for up to 14 days.

\section{Effects of iNOS overexpression on CCSMCs}

As expected, NO concentration in supernatant of ADSCs-iNOS was significantly higher than that of ADSCs and ADSCs-EGFP $(P<0.05)$. Moreover, NO concentration in supernatant of ADSCs-iNOS reached maximum level on the 7 th day $(P<0.05$, Fig. $3 \mathrm{~A})$. We detected the effect of ADSC-iNOS on CCSMCs using Transwell co-culture model. The expression of collagen I and collagen IV in CCSMCs significantly increased in high glucose concentration $(P<0.05)$. However, significant reduction of collagen I and collagen IV expression was observed in CCSMCs co-cultured with ADSCs-iNOS ( $P<0.05$, Fig. 3B, 3C and 3D). In addition, we found that TGF- $\beta 1$ expression in CCSMCs reduced following co-culture with ADSCs-iNOS $(P<0.05$, Fig. 3E).

\section{Effects of ADSCs-iNOS on erectile function}

Finally we evaluated the effects of ADSCs-iNOS on erectile function of DMED rats. There was no significant difference in initial body weight or serum glucose concentration among the 5 groups of rats. 14 days after the induction of diabetes, body weight was significantly lower and fasting glucose concentration was significantly higher in the diabetic rats than the age-matched control rats $(P<0.05)$. However, there were no significant differences in body weight or serum glucose concentration among DMED, ADSCs, ADSCs-EGFP and ADSCs-iNOS groups (Table 1).

Erectile function was measured 2 weeks after ADSCs transplantation. The ICP/MAP ratio was significantly lower in DMED group than that in control group. Intracavernous injection of ADSCs or ADSCs-EGFP significantly improved erectile function of DMED rats. The ICP/MAP ratio of ADSCs-iNOS group was markedly elevated compared to DMED, ADSCs and ADSCsEGFP groups (all $P<0.05$, Fig. 4A and 4B). In addition, NO and cGMP concentrations in penile tissues of ADSCs and ADSCs-EGFP groups were significantly elevated compared to DMED group, although they were still significant lower compared to ADSCs-iNOS group $(P<0.05$, Fig. 4C and 4D). The mean collagen/smooth muscle cell ratio significantly increased in the DMED rats compared to the control rats $(P<0.05)$. Intracavernous injection of ADSCs or ADSCs-EGFP attenuated collagen content $(P<0.05)$. Furthermore, mean collagen/smooth muscle cell ratio in

PeerJ reviewing PDF | (2019:04:36384:2:0:NEW 15 Jul 2019) 
263

264

265

\section{6}

267

268

269

270

271

272

273

274

275

276

277

278

279

280

281

282

283

284

285

286

287

288

289

290

291

292

293

294

295

296

297

298

299

300

301

302

ADSCs-iNOS treated rats was significantly lower than that in ADSCs or ADSCs-EGFP group $(P<0.05)$ (Fig. 4E-I and 4J).

\section{Discussion}

In this study we demonstrated that infection of ADSCs with adenovirus containing iNOS expression cassette led to significantly high expression of iNOS and increased generation of NO. ADSCs played a positive role in restoring DMED in rats. Furthermore, overexpression of iNOS in ADSCs was shown to achieve a significantly larger improvement of erectile function. The therapeutic effect may be achieved by increased NO generation and the suppression of collagen I and collagen IV expression in the CCSMCs to decrease penile fibrosis.

Corpus cavernosum is composed of a loose trabecular meshwork of smooth muscle and connective tissues, which are structural basis of erectile function. Ryu et al found that collagen fiber content was significantly increased in corpus cavernosum of patients with vasculogenic ED (Ryu et al., 2004). Further studies demonstrated that extracellular matrix such as fibronectin, collagen IV and collagen I accumulated and collagen I/collagen III ratio was decreased in the corpus cavernosum tissue of diabetic ED rats (Hirata et al., 2009; Zhou et al., 2012). Abnormal extracellular matrix can cause mechanical alterations of corpus cavernosum, which may provoke penile venous leakage, leading to vasculogenic ED ( $\mathrm{Li}$ et al., 2013). Increased expression of TGF- $\beta 1$ pathway could be involved in collagen fiber accumulation and penile fibrosis (Ryu et al., 2004). CCSMCs are the prdominant mesenchymal cell type in the corpus cavernosum. Synthesis of connective tissue proteins and collagen by CCSMCs was significantly increased by exogenous TGF- $\beta 1$ (Moreland et al., 1995). In accordance with previous studies, our study showed that collagen I and collagen IV expression in CCSMCs significantly increased under high glucose condition and penile fibrosis significantly increased in DMED rats. Then we co-cultured CCSMCs with ADSCs, and found significantly decreased synthesis of collagen I and collagen IV. Furthermore, we found that TGF- $\beta 1$ expression in CCSMCs significantly decreased, indicating the involvement of TGF- $\beta 1$ signaling pathway. However, further studies are needed to elucidate precise mechanism of ADSCs' effect on CCSMCs. In vivo, ADSCs ameliorated penile fibrosis in ED rats, and the possible mechanism is still needed to be elucidated precisely. ADSCs significantly prevented upregulation of collagen III and elastin in the tunica albuginea of Peyronie's disease rats (Castiglione et al., 2013). Intratunical injection of ADSCs decreased the expression of tissue inhibitors of metalloproteinases, and promoted the expression and activity of matrix metalloproteinases (Gokce et al., 2014). In addition, exosomes from ADSCs were enriched with miR-132 and miR- let7 which played antifibrotic role through regulating TGF- $\beta 1$ pathway (Zhu et al., 2017).

NO/cGMP signaling pathway plays a crucial role of in erectile function. NO released from nonadrenergic noncholinergic nerves and endothelium is the principal mediator of penile erection. Moreover, this pathway plays an important role in ameliorating tissue fibrosis. Marta et al found that NO inhibited TGF- $\beta /$ Smad induced gene transactivation in a cGMP-dependent manner in endothelial cells, leading to proteasomal degradation of phosphorylated Smad. In 
303

304

305

306

307

308

309

310

311

312

313

314

315

316

317

318

319

320

321

322

323

324

325

326

327

328

329

330

331

332

333

334

335

336

337

338

339

340

341

342

addition, NO reduced and delayed nuclear translocation of activated Smad (Saura et al., 2005). cGMP significantly reduced TGF- $\beta$ induced upregulation of collagen I and collagen II at mRNA and protein levels (Beyer et al., 2015). In this study, we found that iNOS overexpression in ADSCs significantly enhanced NO generation and could last for 14 days. Compared to ADSCs, ADSCs-iNOS significantly increased NO and cGMP concentrations in penile tissues, and decreased collagen I and collagen IV expression in CCSMCs to ameliorate penile fibrosis in DMED rats. These results are consistent with previous studies that the inhibition of iNOS promoted penile fibrosis. For example, Monica et al found that more collagen was deposited in corpus cavernosum of iNOS knockout mouse. In addition, inactivation of iNOS gene led to exacerbated penile fibrosis in DM mouse by increasing oxidative stress and TGF- $\beta 1$ expression under hyperglycemia condition (Ferrini et al., 2010). Similarly, L-NIL as an inhibitor of iNOS activity increased oxidative stress and fibrosis in the media of arteries (Ferrini et al., 2004).

However, other studies suggested that erectile function was impaired by iNOS expression. The induction of iNOS accompanying penile fibrosis was demonstrated in rat models of DMED, Peyronie's disease and aging-related ED (Bivalacqua et al., 2000; Ferrini et al., 2001; Usta et al., 2003). In addition, iNOS inhibition improved erectile function in Peyronie's disease or DMED rat. However, the application of aminoguanidine as an iNOS inhibitor was not appropriate, because aminoguanidine inhibited not only all three kinds of NOS, but also advanced glycation end products involved in tissue fibrosis. Moreover, further studies are needed to determine if elevated iNOS expression is possibly a compensatory reflection when eNOS and nNOS expression is decreased under pathological conditions.

There are some limitations in the current study. First, we did not investigate the effect of iNOS expression on the stemness of ADSCs. In our study, more NO was released from ADSCsiNOS than ADSCs. Tapia-Limonchi et al found that NO maintained embryonic stem cells (ESC) pluripotency and delayed ESC differentiation by regulating Gsk3- $\beta / \beta$-catenin and PI3K/Akt signaling pathways (Tapia-Limonchi et al., 2010). The effect of NO released from ADSCs iNOS on ADSC stemness required further investigation. Second, ADSCs were only transplanted into corpus cavernosum once. Repeated injection of ADSCs may achieve better therapeutic effects but need to be confirmed in future studies. Third, we did not compare therapeutic effect of ADSCs-iNOS to that of iNOS alone. Although adenovirus act as efficient agents for gene transfer, they can activate cellular and humoral immune response in the hosts, which limits the safety and efficacy in vivo. The innate immune response is mediated by the adenovirus particle, but not viral transcription (Muruve, 2004). In contrast, transplanted stem cells could suppress excessive immune response (Lin, Lin \& Lue, 2012). ADSCs overexpressing iNOS may be safer and more efficient than iNOS alone. Fourth, the statistical power for this study was relatively low $(49.9 \%)$ which may be due to the small group size, and more experimental rats will be included to validate these results in our further study. Fifth, our study did not detect distinct downstream pathways of TGF- $\beta 1$ to determine the precise mechanism of ADSCs-iNOS' effect on CCSMCs. A separate but more extensive experiment on this topic will be carried out.

\section{Conclusions}

Peer) reviewing PDF | (2019:04:36384:2:0:NEW 15 Jul 2019) 
343

344

345

346

347

348

349

350

351

352

353

354

355

356

357

358

359

360

361

362

363

364

365

366

367

368

369

370

371

372

373

374

375

376

377

378

379

380

381

382

In conclusion, intracavernous administration of ADSCs-iNOS improved erectile function of DMED rats. Injection of ADSCs-iNOS in a rat model of DM significantly decreased penile fibrosis, possibly due to increased NO generation and suppressed expression of collagen I and collagen IV in the CCSMCs.

\section{References}

Alagesan S, and Griffin MD. 2014. Autologous and allogeneic mesenchymal stem cells in organ transplantation: what do we know about their safety and efficacy? Current Opinion in Organ Transplantation 19:65-72 DOI: 10.1097/MOT.0000000000000043.

Beyer C, Zenzmaier C, Palumbo-Zerr K, Mancuso R, Distler A, Dees C, Zerr P, Huang J, Maier C, Pachowsky ML, Friebe A, Sandner P, Distler O, Schett G, Berger P, and Distler JH. 2015. Stimulation of the soluble guanylate cyclase $(\mathrm{sGC})$ inhibits fibrosis by blocking non-canonical TGFbeta signalling. Annals of the Rheumatic Diseases 74:1408-1416 DOI: 10.1136/annrheumdis-2013-204508.

Bivalacqua TJ, Diner EK, Novak TE, Vohra Y, Sikka SC, Champion HC, Kadowitz PJ, and Hellstrom WJ. 2000. A rat model of Peyronie's disease associated with a decrease in erectile activity and an increase in inducible nitric oxide synthase protein expression. Journal of Urology 163:1992-1998

Castiglione F, Hedlund P, Van der Aa F, Bivalacqua TJ, Rigatti P, Van Poppel H, Montorsi F, De Ridder D, and Albersen M. 2013. Intratunical injection of human adipose tissue-derived stem cells prevents fibrosis and is associated with improved erectile function in a rat model of Peyronie's disease. European Urology 63:551-560. DOI:10.1016/j.eururo.2012.09.034.

Chen F, Zhang H, Wang Z, Ding W, Zeng Q, Liu W, Huang C, He S, and Wei A. 2017. Adipose-Derived Stem CellDerived Exosomes Ameliorate Erectile Dysfunction in a Rat Model of Type 2 Diabetes. Journal of Sexual Medicine 14:1084-1094 DOI: 10.1016/j.jsxm.2017.07.005.

Chen R, Wang T, Rao K, Yang J, Zhang S, Wang S, Liu J, and Ye Z. 2011. Up-regulation of VEGF by small activator RNA in human corpus cavernosum smooth muscle cells. Journal of Sexual Medicine 8:2773-2780 DOI: 10.1111/j.1743-6109.2011.02412.x.

Cheng E. 2007. Real-life safety and efficacy of vardenafil in the treatment of erectile dysfunction-results from 30,010 U.S. patients. Journal of Sexual Medicine 4:432-439 DOI: 10.1111/j.1743-6109.2006.00383.x.

Davila HH, Magee TR, Vernet D, Rajfer J, and Gonzalez-Cadavid NF. 2004. Gene transfer of inducible nitric oxide synthase complementary DNA regresses the fibrotic plaque in an animal model of Peyronie's disease. Biology of Reproduction 71:1568-1577 DOI: 10.1095/biolreprod.104.030833.

Eissa NT, Yuan JW, Haggerty CM, Choo EK, Palmer CD, and Moss J. 1998. Cloning and characterization of human inducible nitric oxide synthase splice variants: a domain, encoded by exons 8 and 9, is critical for dimerization. Proceedings of the National Academy of Sciences of the United States of America 95:76257630. DOI:10.1073/pnas.95.13.7625.

Ferrini M, Magee TR, Vernet D, Rajfer J, and Gonzalez-Cadavid NF. 2001. Aging-related expression of inducible nitric oxide synthase and markers of tissue damage in the rat penis. Biology of Reproduction 64:974-982

Ferrini MG, Davila HH, Valente EG, Gonzalez-Cadavid NF, and Rajfer J. 2004. Aging-related induction of inducible nitric oxide synthase is vasculo-protective to the arterial media. Cardiovascular Research 61:796-805 DOI: 10.1016/j.cardiores.2003.12.006.

Peer) reviewing PDF | (2019:04:36384:2:0:NEW 15 Jul 2019) 
383

384

385

386

387

388

389

390

391

392

393

394

395

396

397

398

399

400

401

402

403

404

405

406

407

408

409

410

411

412

413

414

415

416

417

418

419

420

421

422

423

Ferrini MG, Rivera S, Moon J, Vernet D, Rajfer J, and Gonzalez-Cadavid NF. 2010. The genetic inactivation of inducible nitric oxide synthase (iNOS) intensifies fibrosis and oxidative stress in the penile corpora cavernosa in type 1 diabetes. Journal of Sexual Medicine 7:3033-3044 DOI: 10.1111/j.17436109.2010.01884.x.

Garcia MM, Fandel TM, Lin G, Shindel AW, Banie L, Lin CS, and Lue TF. 2010. Treatment of erectile dysfunction in the obese type 2 diabetic ZDF rat with adipose tissue-derived stem cells. Journal of Sexual Medicine 7:8998

Gokce A, Abd Elmageed ZY, Lasker GF, Bouljihad M, Kim H, Trost LW, Kadowitz PJ, Abdel-Mageed AB, Sikka SC, and Hellstrom WJ. 2014. Adipose tissue-derived stem cell therapy for prevention and treatment of erectile dysfunction in a rat model of Peyronie's disease. Andrology 2:244-251 DOI: 10.1111/j.20472927.2013.00181.x.

Gonzalez-Cadavid NF, and Rajfer J. 2010. Treatment of Peyronie's disease with PDE5 inhibitors: an antifibrotic strategy. Nature Reviews Urology 7:215-221 DOI: 10.1038/nrurol.2010.24.

Hirata H, Kawamoto K, Kikuno N, Kawakami T, Kawakami K, Saini S, Yamamura S, and Dahiya R. 2009. Restoring erectile function by antioxidant therapy in diabetic rats. Journal of Urology 182:2518-2525 DOI: 10.1016/j.juro.2009.07.009.

Johannes CB, Araujo AB, Feldman HA, Derby CA, Kleinman KP, and McKinlay JB. 2000. Incidence of erectile dysfunction in men 40 to 69 years old: longitudinal results from the Massachusetts male aging study. Journal of Urology 163:460-463

Li WJ, Wang H, Zhou J, Li B, Zhang J, Lu M, and Wang Z. 2013. P144, A TGF-beta1 antagonist peptide, synergizes with sildenafil and enhances erectile response via amelioration of cavernosal fibrosis in diabetic rats. Journal of Sexual Medicine 10:2942-2951 DOI: 10.1111/jsm.12325.

Lin CS, Lin G, and Lue TF. 2012. Allogeneic and xenogeneic transplantation of adipose-derived stem cells in immunocompetent recipients without immunosuppressants. Stem Cells and Development 21:2770-2778 DOI: $10.1089 / \mathrm{scd} .2012 .0176$.

Moreland RB, Traish A, McMillin MA, Smith B, Goldstein I, and Saenz de Tejada I. 1995. PGE1 suppresses the induction of collagen synthesis by transforming growth factor-beta 1 in human corpus cavernosum smooth muscle. Journal of Urology 153:826-834

Muruve DA. 2004. The innate immune response to adenovirus vectors. Human Gene Therapy 15:1157-1166 DOI: 10.1089/hum.2004.15.1157.

Qiu X, Lin H, Wang Y, Yu W, Chen Y, Wang R, and Dai Y. 2011. Intracavernous transplantation of bone marrowderived mesenchymal stem cells restores erectile function of streptozocin-induced diabetic rats. Journal of Sexual Medicine 8:427-436 DOI: 10.1111/j.1743-6109.2010.02118.x.

Ryu JK, Han JY, Chu YC, Song SU, Lee KH, Yoon SM, Suh JK, and Kim SJ. 2004. Expression of cavernous transforming growth factor-beta1 and its type II receptor in patients with erectile dysfunction. International Journal of Andrology 27:42-49

Ryu JK, Tumurbaatar M, Jin HR, Kim WJ, Kwon MH, Piao S, Choi MJ, Yin GN, Song KM, Kang YJ, Koh YJ, Koh GY, and Suh JK. 2012. Intracavernous delivery of freshly isolated stromal vascular fraction rescues erectile function by enhancing endothelial regeneration in the streptozotocin-induced diabetic mouse. Journal of Sexual Medicine 9:3051-3065 DOI: 10.1111/j.1743-6109.2012.02962.x.

Saura M, Zaragoza C, Herranz B, Griera M, Diez-Marques L, Rodriguez-Puyol D, and Rodriguez-Puyol M. 2005. Nitric

Peer) reviewing PDF | (2019:04:36384:2:0:NEW 15 Jul 2019) 
424

425

426

427

428

429

430

431

432

433

434

435

436

437

438

439

440

441

442

443

444

445

446

447

448

449

450

451

452

453

454

455

456

457

458

459 oxide regulates transforming growth factor-beta signaling in endothelial cells. Circulation Research 97:1115-1123 DOI: 10.1161/01.RES.0000191538.76771.66.

Sowa Y, Imura T, Numajiri T, Nishino K, and Fushiki S. 2012. Adipose-derived stem cells produce factors enhancing peripheral nerve regeneration: influence of age and anatomic site of origin. Stem Cells and Development 21:1852-1862 DOI: 10.1089/scd.2011.0403.

Sun C, Lin H, Yu W, Li X, Chen Y, Qiu X, Wang R, and Dai Y. 2012. Neurotrophic effect of bone marrow mesenchymal stem cells for erectile dysfunction in diabetic rats. International Journal of Andrology 35:601-607 DOI: 10.1111/j.1365-2605.2012.01250.x.

Tapia-Limonchi R, Cahuana GM, Caballano-Infantes E, Salguero-Aranda C, Beltran-Povea A, Hitos AB, Hmadcha A, Martin F, Soria B, Bedoya FJ, and Tejedo JR. 2016. Nitric Oxide Prevents Mouse Embryonic Stem Cell Differentiation Through Regulation of Gene Expression, Cell Signaling, and Control of Cell Proliferation. Journal of Cellular Biochemistry 117:2078-2088 DOI: 10.1002/jcb.25513.

Thorve VS, Kshirsagar AD, Vyawahare NS, Joshi VS, Ingale KG, and Mohite RJ. 2011. Diabetes-induced erectile dysfunction: epidemiology, pathophysiology and management. Journal of Diabetes and Its Complications 25:129-136 DOI: 10.1016/j.jdiacomp.2010.03.003.

Usta MF, Bivalacqua TJ, Yang DY, Ramanitharan A, Sell DR, Viswanathan A, Monnier VM, and Hellstrom WJ. 2003. The protective effect of aminoguanidine on erectile function in streptozotocin diabetic rats. Journal of Urology 170:1437-1442 DOI: 10.1097/01.ju.0000077557.45582.f3.

Wang T, Li M, Yuan H, Zhan Y, Xu H, Wang S, Yang W, Liu J, Ye Z, and Li LC. 2013. saRNA guided iNOS up-regulation improves erectile function of diabetic rats. Journal of Urology 190:790-798 DOI: 10.1016/j.juro.2013.03.043.

Wang X, Liu C, Li S, Xu Y, Chen P, Liu Y, Ding Q, Wahafu W, Hong B, and Yang M. 2015. Hypoxia precondition promotes adipose-derived mesenchymal stem cells based repair of diabetic erectile dysfunction via augmenting angiogenesis and neuroprotection. PloS One 10:e0118951 DOI: 10.1371/journal.pone.0118951.

Yang J, Wang T, Rao K, Zhan Y, Chen RB, Liu Z, Li MC, Zhuan L, Zang GH, Guo SM, Xu H, Wang SG, Liu JH, and Ye ZQ. 2013. S-allyl cysteine restores erectile function through inhibition of reactive oxygen species generation in diabetic rats. Andrology 1:487-494 DOI: 10.1111/j.2047-2927.2012.00060.x.

Zhang Y, Chen Z, Wang T, Yang J, Li R, Wang S, Liu J, and Ye Z. 2016. Treatment of diabetes mellitus-induced erectile dysfunction using endothelial progenitor cells genetically modified with human telomerase reverse transcriptase. Oncotarget 7:39302-39315 DOI: 10.18632/oncotarget.9909.

Zhou F, Li GY, Gao ZZ, Liu J, Liu T, Li WR, Cui WS, Bai GY, and Xin ZC. 2012. The TGF-beta1/Smad/CTGF pathway and corpus cavernosum fibrous-muscular alterations in rats with streptozotocin-induced diabetes. Journal of Andrology 33:651-659 DOI: 10.2164/jandrol.111.014456.

Zhu LL, Huang X, Yu W, Chen H, Chen Y, and Dai YT. 2017. Transplantation of adipose tissue-derived stem cellderived exosomes ameliorates erectile function in diabetic rats. Andrologia DOI: 10.1111/and.12871.

Peerj reviewing PDF | (2019:04:36384:2:0:NEW 15 Jul 2019) 


\section{Figure 1}

Figure 1. Primary culture and characterization of rat ADSCS and CCSCMs.

(A) Morphological features of ADSCs at passage 1 (primary magnification: $\times 100$ ) . (B) Morphological features of ADSCs at passage 4 (primary magnification: $\times 100$ ). (C-K) ADSCS were identified by flow cytometry at passage 4. (L) Adipogenic differentiation of ADSCS assessed by oil red-O staining (primary magnification: $\times 200$ ). (M) Myogenic differentiation of ADSCs assessed by immunofluorescence staining with $\alpha$-SMA antibody (green, primary magnification: $\times 200$ ). (N) Morphological features of CCSMCs after purification (primary magnification: $\times 100$ ) . (0) CCSMCs were assessed by immunostaining with $\alpha$-SMA antibody (red, primary magnification: $\times 100$ ). The nuclei were labeled with DAPI (blue). 

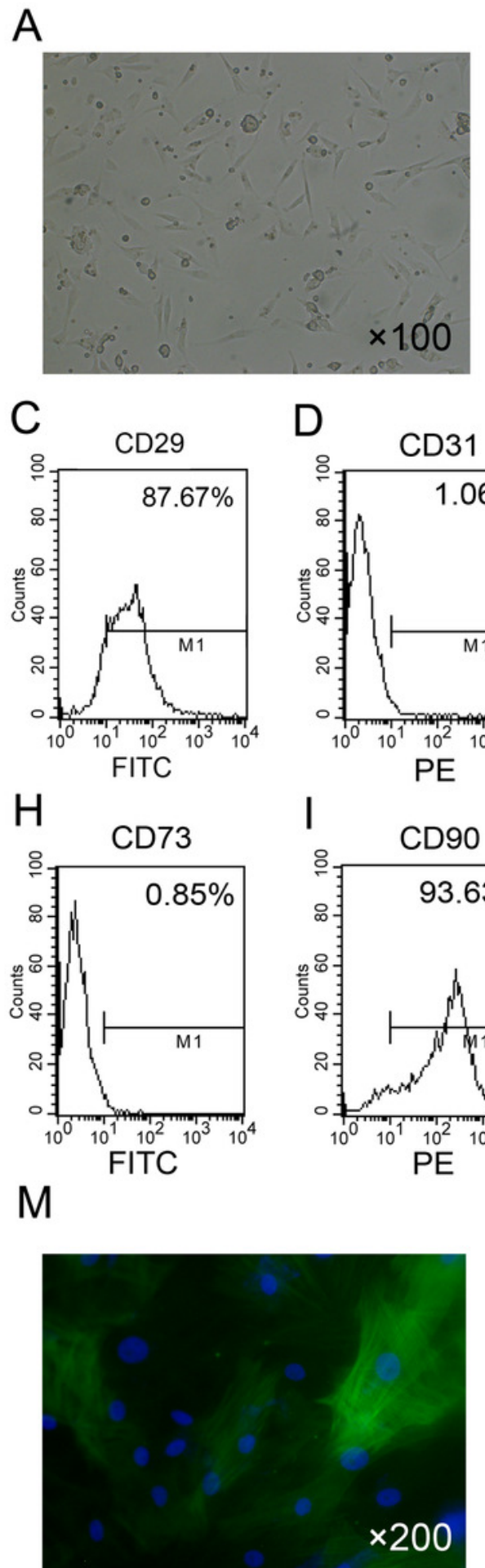

B
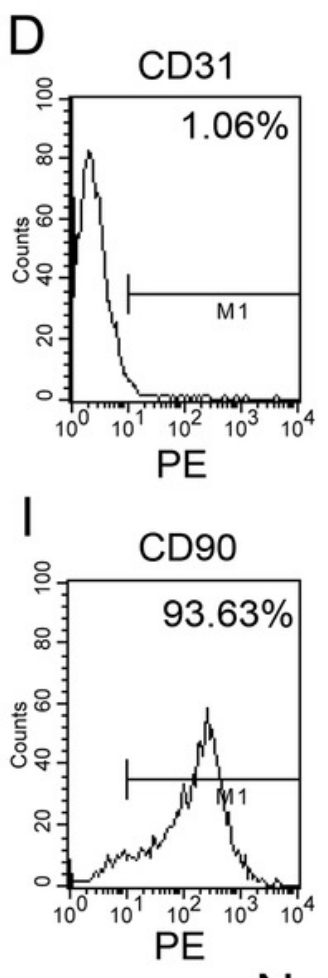

$\mathrm{N}$

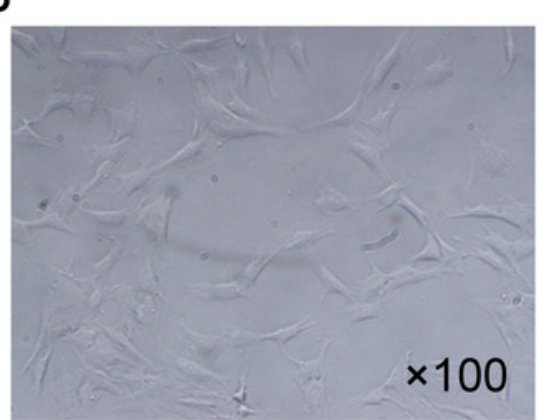

E $\quad 5034 \quad F$

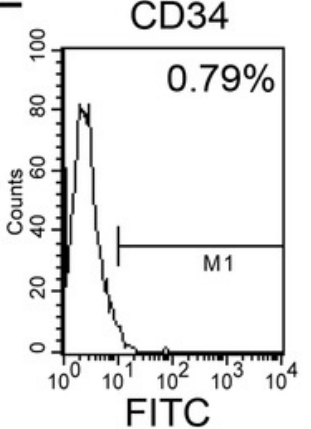

$\mathrm{J} \quad \mathrm{CD} 105$

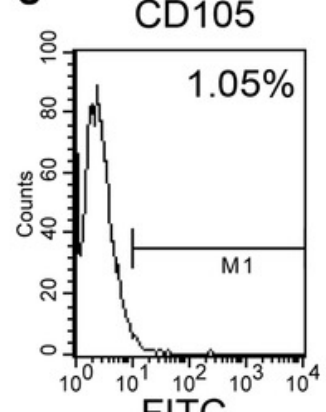

FITC

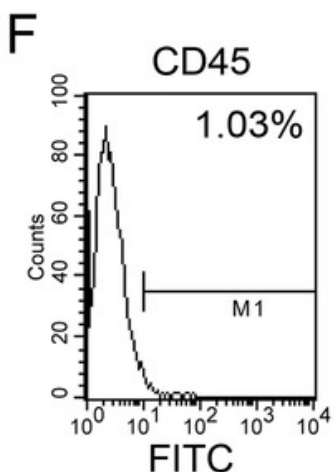

K

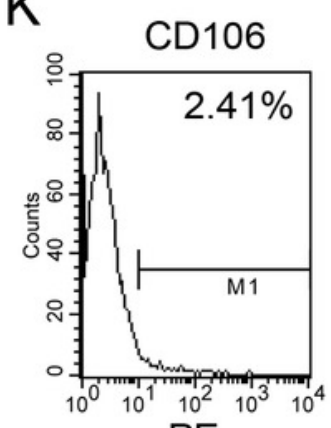

$\mathrm{PE}$ $\times 200$
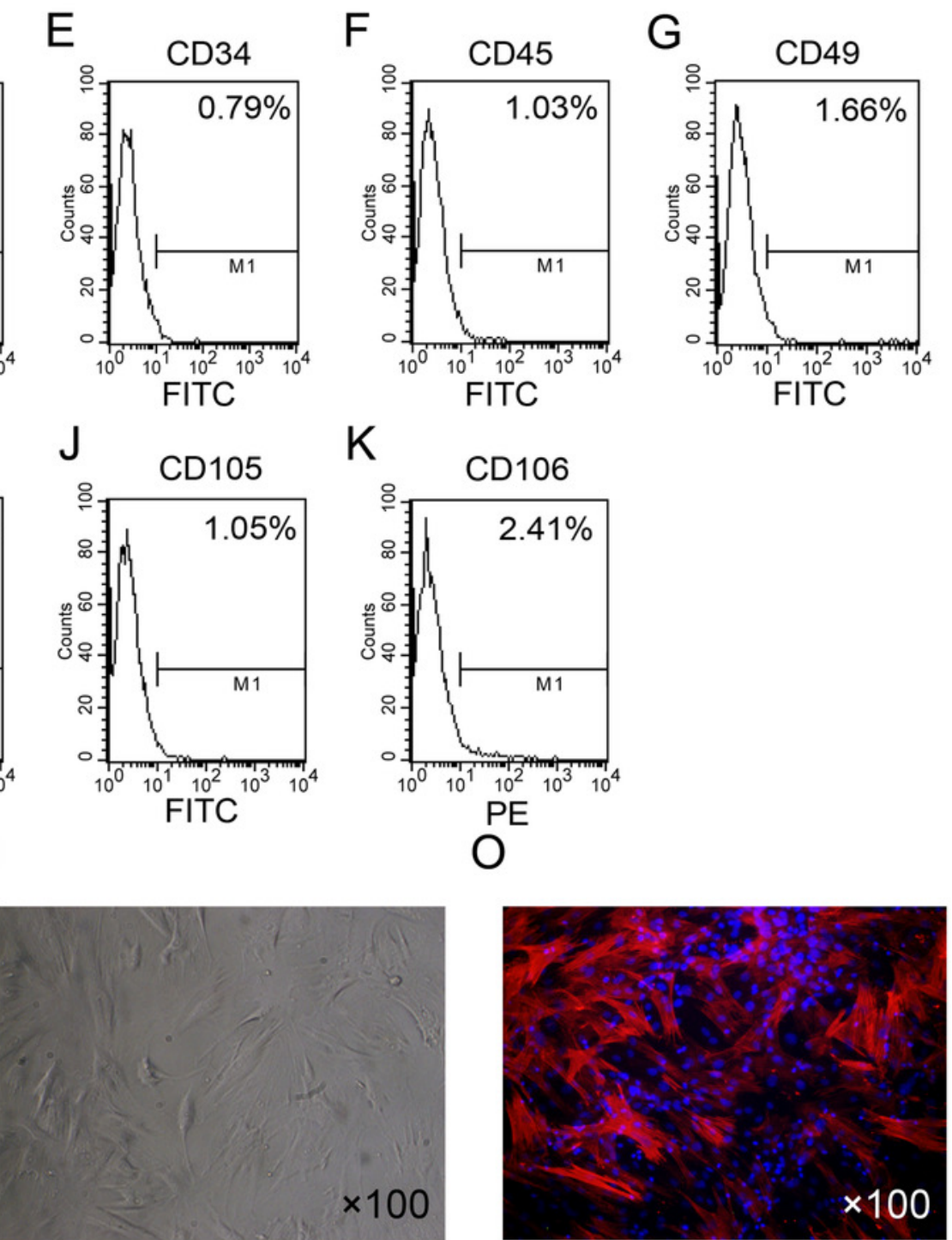


\section{Figure 2}

Figure 2. iNOS expression in ADSCs.

(A-C) EGFP-expressing ADSCs were observed by fluorescence microscopy 3 days after infection (primary magnification: $\times 100$ ). (D) iNOS expression at mRNA level was detected by real-time PCR and the relative ratio of $\mathrm{iNOS} / \beta$-actin measured in ADSCs was arbitrarily presented as 1. Data are the mean of 3 independent experiments. (E) iNOS expression at protein level was detected by Western blot analysis. Data are the mean of 3 independent experiments. ${ }^{*} P<0.05$ vs. ADSCs, ${ }^{\circledR} P<0.05$ vs. ADSCs-EGFP 


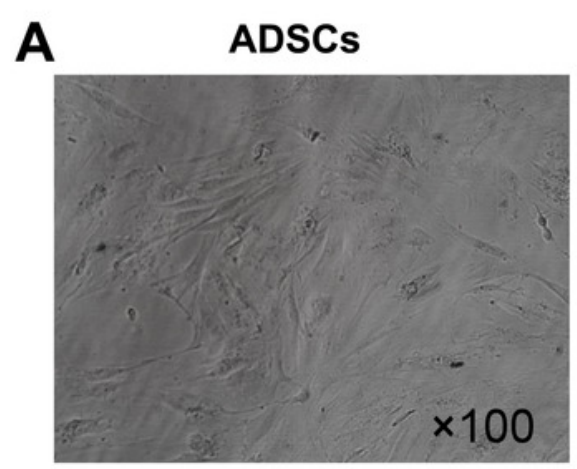

B

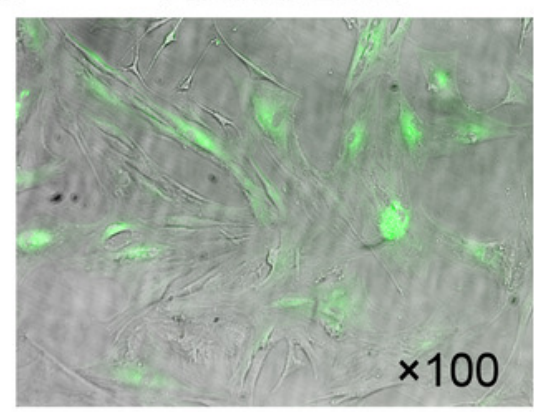

C ADSCs-inOS

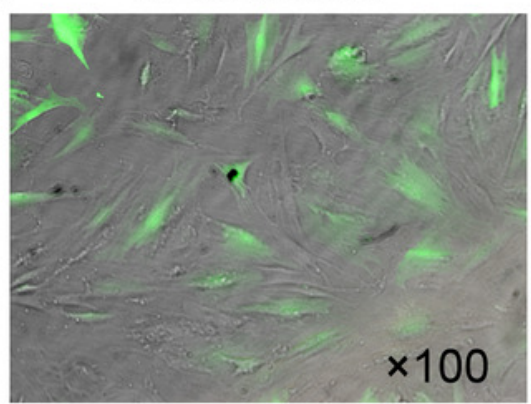

D

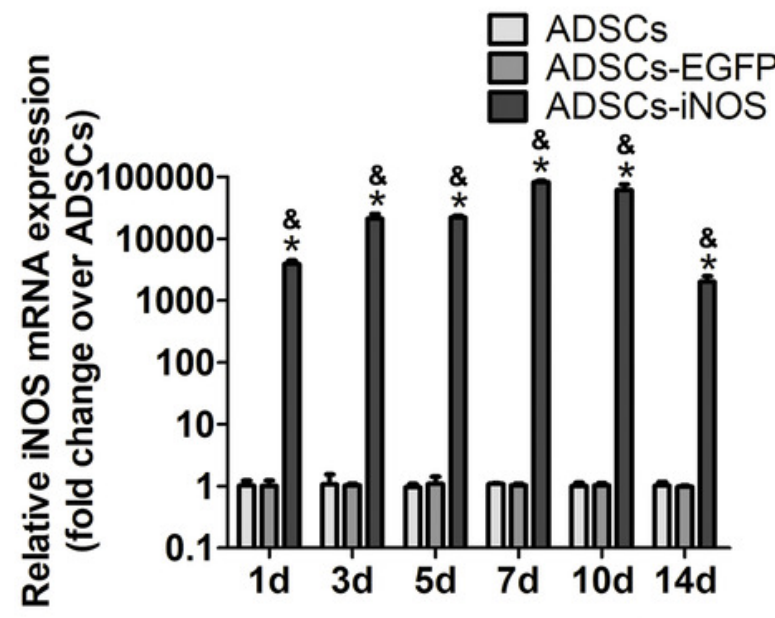

E

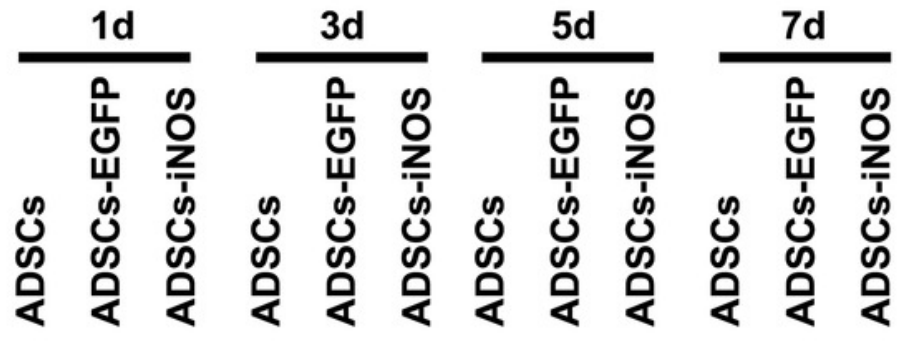

iNOS
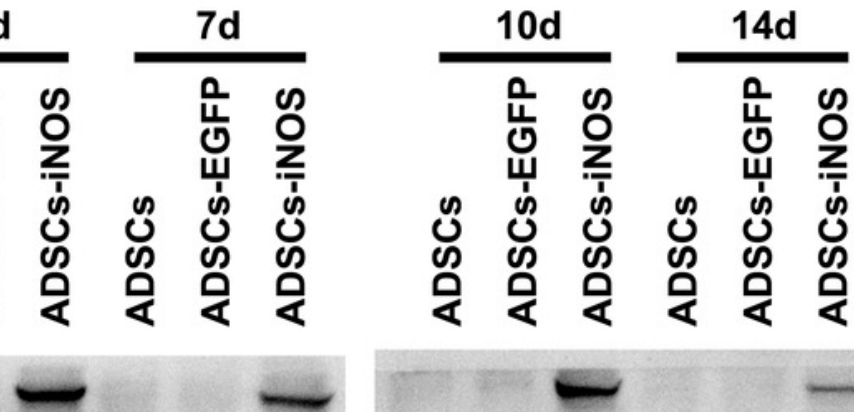

$\beta$-actin 


\section{Figure 3}

Figure 3. Characterization of ADSCs-iNOS.

(A) NO concentration in supernatant of ADSCs was measured after incubation in $10 \mathrm{mmol} / \mathrm{L} \mathrm{L}$ Arginine for 24 hours. Data are the mean of 3 independent experiments. (B) The protein expression of collagen I, collagen IV and TGF- $\beta 1$ in CCSMCs was detected by Western blot analysis after 7 days of co-culture. (C) Data were shown as the relative density values of collagen I to $\beta$-actin as loading control. Data are the mean of 3 independent experiments. (D) Data were shown as the relative density values of collagen IV to $\beta$-actin as loading control. Data are the mean of 3 independent experiments. (E) Data were shown as the relative density values of TGF- $\beta 1$ to $\beta$-actin as loading control. Data are the mean of 3 independent experiments. ${ }^{*} P<0.05$ vs. ADSCs, ${ }^{5} P<0.05$ vs. ADSCs-EGFP, ${ }^{*} P<0.05$ vs. CCSMCs, ${ }^{\circledR} P<0.05$ vs. CCSMCs cultured in DMEM containing $30 \mathrm{mM}$ glucose, ${ }^{S} P<0.05$ vs. CCSMCs co-cultured with ADSCs, ${ }^{\oplus} P<0.05$ vs. CCSMCs co-cultured with ADSCs-EGFP. 
A

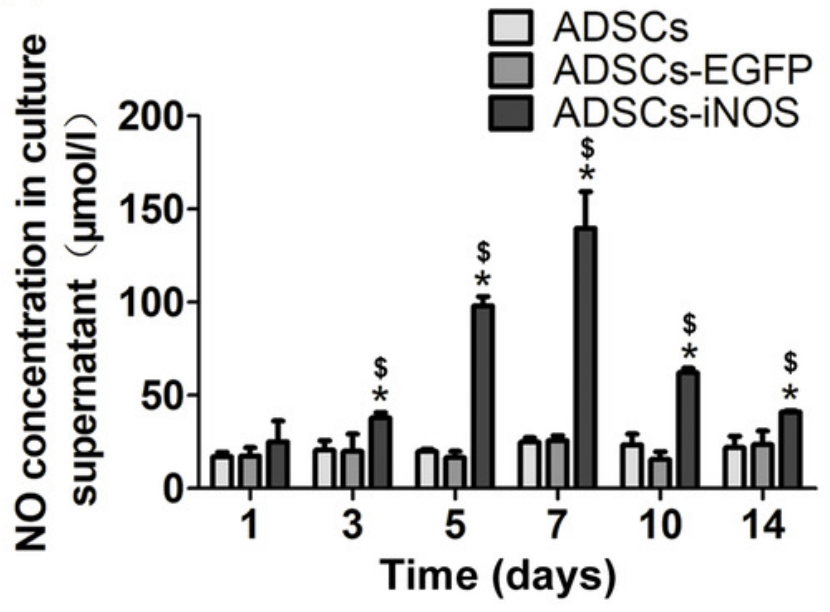

C

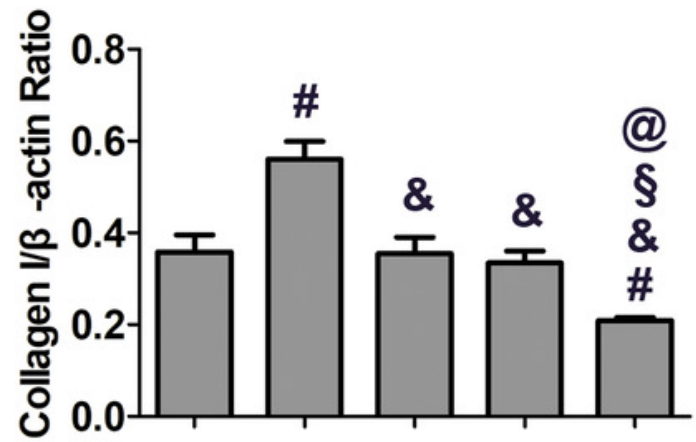

CCSMCs +++++ $30 \mathrm{mM}$ glucose -++++ $\begin{array}{rlllll}\text { ADSCS } & - & - & \pm & - & - \\ \text { ADSCS-EGFP } & - & - & - & \mathbf{+} & \mathbf{+}\end{array}$

E

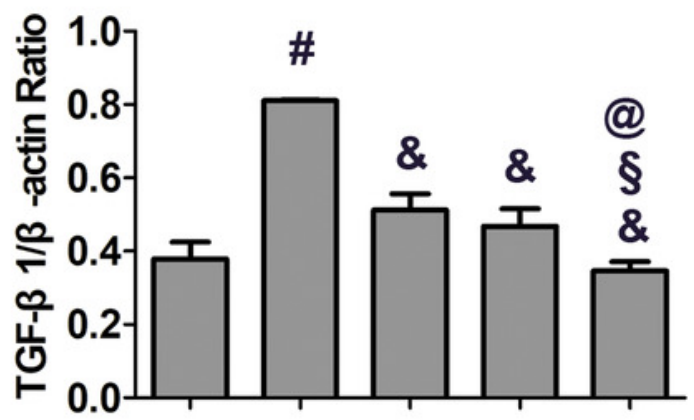

$\begin{array}{rlllll}\text { CCSMCs } & \mathbf{+} & \mathbf{+} & \mathbf{+} & \mathbf{+} & \mathbf{+} \\ \text { 30mM glucose } & - & \mathbf{+} & \mathbf{+} & \mathbf{+} & \mathbf{+} \\ \text { ADSCS } & - & \mathbf{-} & \mathbf{+} & \mathbf{+} & \mathbf{-} \\ \text { ADSCS-EGFP } & - & - & - & - & \mathbf{+}\end{array}$

B

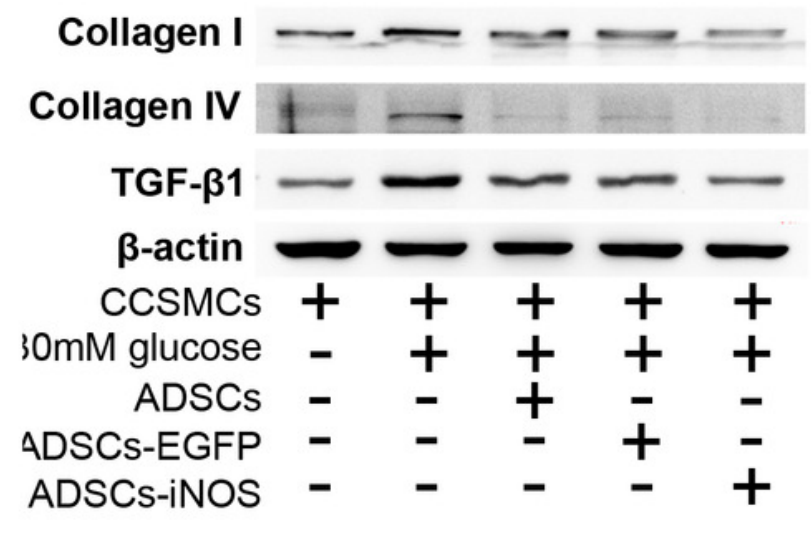

D

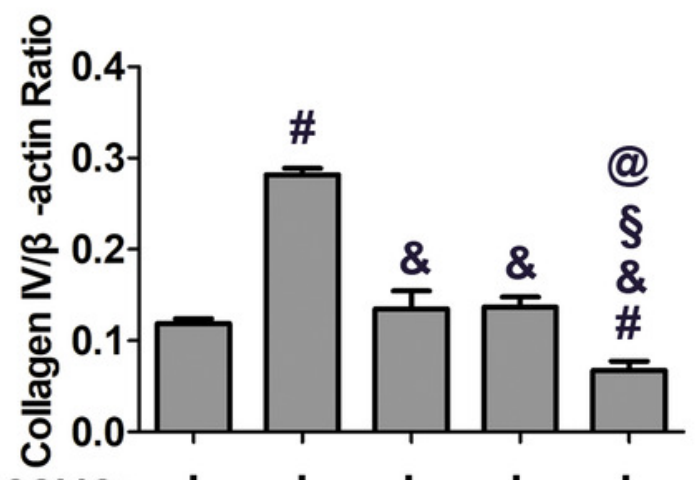

$\operatorname{ccsmCs}+++++$ 30mM glucose -++++ ADSCS $= \pm \pm \pm=$ $\begin{array}{llllll}\text { ADSCS-EGFP } & - & - & \mathbf{1} & \mathbf{1} \\ \text { ADSCS-iNOS } & - & - & - & - & +\end{array}$ 


\section{Figure 4}

Figure 4. The transplantation of ADSCs-iNOS improved erectile function of DMED rats.

(A) MAP and ICP response to electrostimulation of cavernous nerves (5 Volts, 1 minute). (B) ICP/MAP ratio in control, DMED, ADSCs, ADSCs-EGFP and ADSCs-iNOS groups. (C) NO concentration in penile tissues of each group. Data are the mean of 4 rats per group. (D) ELISA assay of CGMP concentration in penile tissues of each group. Data are the mean of 4 rats per group. (E-I) Penile tissues were stained with Masson trichrome in all groups. Collagen fibers were stained blue, while smooth muscle was stained red (primary magnification: $\times 100$ ). (J) The collagen to smooth muscle ratio in penile tissues of each group. Data are the mean of 5 rats per group. ${ }^{*} P<0.05$ vs. control group, ${ }^{\sharp} P<0.05$ vs. DMED group, ${ }^{\circledR} P<0.05$ vs. ADSCs group ${ }^{s} P<0.05$ vs. ADSCs-EGFP. 

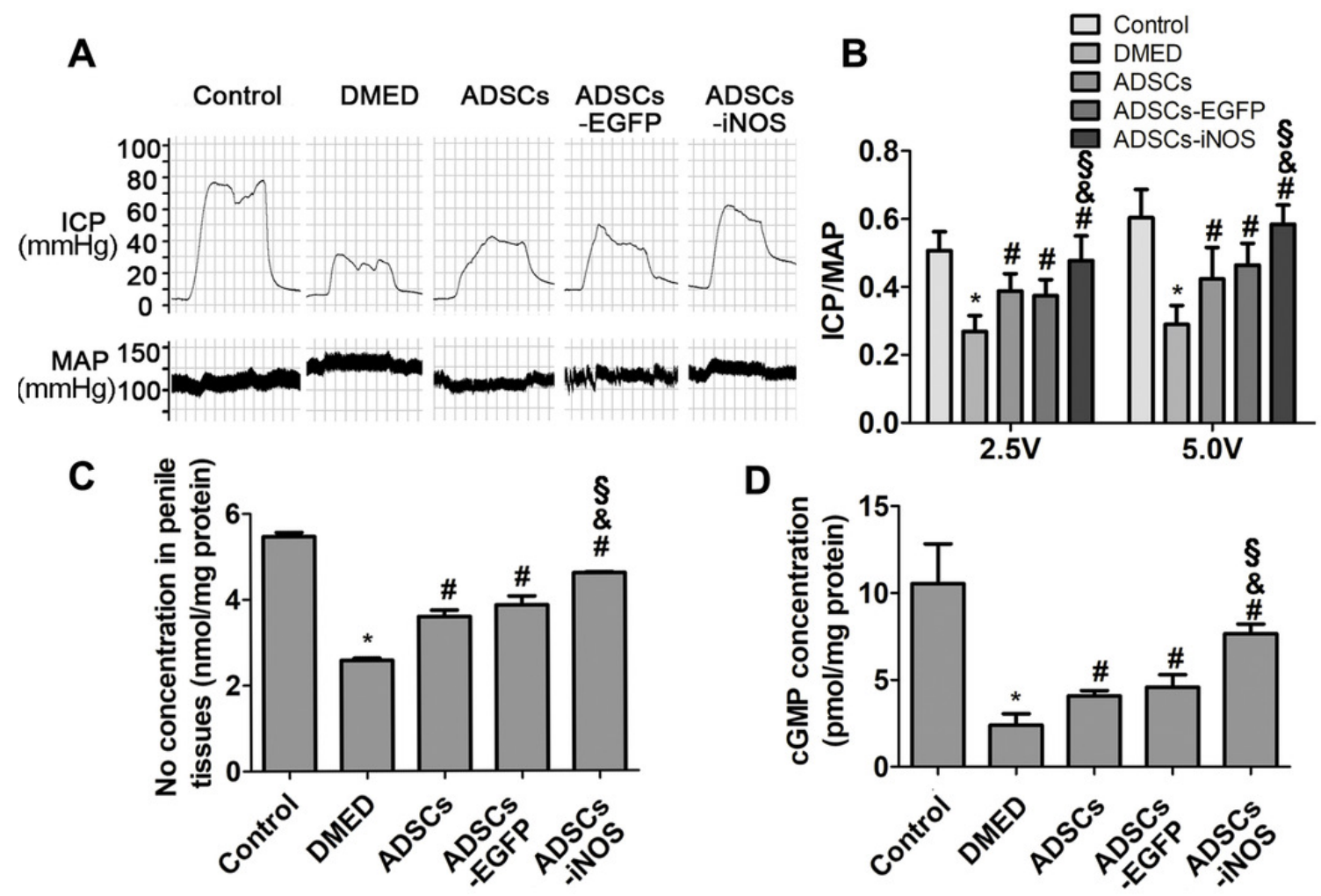

D
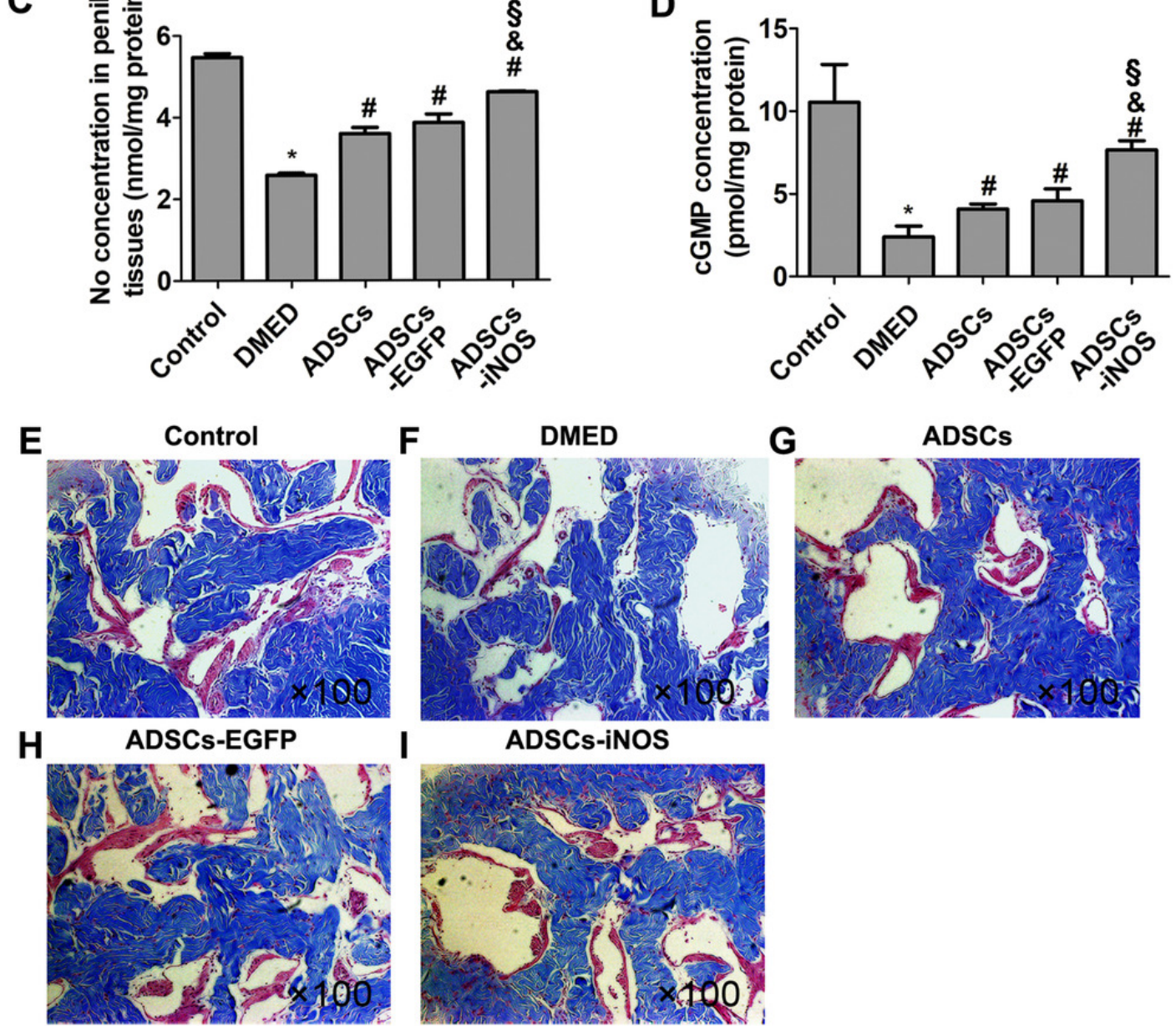

J

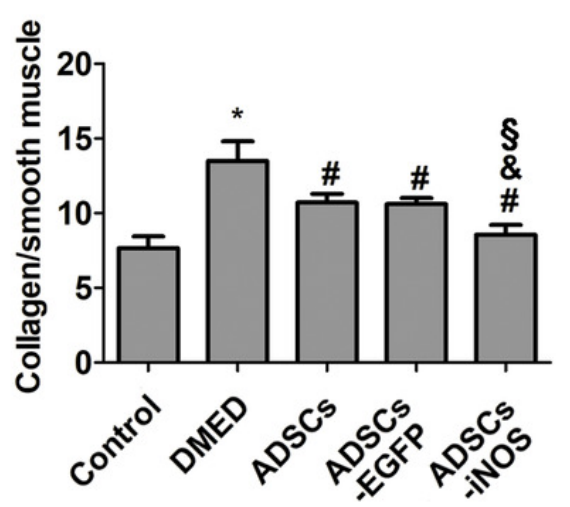




\section{Table $\mathbf{1}$ (on next page)}

Table 1. Metabolic and physiological variables of experimental rats 


\begin{tabular}{cccccc}
\hline Variable & Control & DMED & ADSCs & $\begin{array}{c}\text { ADSCs- } \\
\text { EGFP }\end{array}$ & ADSCs-iNOS \\
\hline $\begin{array}{c}\text { Initial weight } \\
(\mathrm{g})\end{array}$ & $268.0 \pm 12.7$ & $268.9 \pm 8.6$ & $268.4 \pm 7.9$ & $266.6 \pm 12.9$ & $270.7 \pm 11.3$ \\
$\begin{array}{c}\text { Final weight } \\
(\mathrm{g})\end{array}$ & $596.0 \pm 54.5$ & $274.8 \pm 18.1^{*}$ & $284.5 \pm 22.3^{*}$ & $281.8 \pm 17.3^{*}$ & $285.1 \pm 18.8^{*}$ \\
$\begin{array}{c}\text { Initial fasting } \\
\text { glucose (mmol/L) } \\
\text { Final fasting }\end{array}$ & $6.3 \pm 0.5$ & $6.2 \pm 0.3$ & $6.2 \pm 0.4$ & $6.2 \pm 0.5$ & $6.2 \pm 0.4$ \\
$\begin{array}{c}\text { glucose (mmol/L) } \\
\text { MAP (mmHg) }\end{array}$ & $104.4 \pm 5.7$ & $30.8 \pm 2.0^{*}$ & $29.4 \pm 2.1^{*}$ & $30.3 \pm 1.6^{*}$ & $30.0 \pm 2.8^{*}$ \\
\hline
\end{tabular}

1

Note: DMED, diabetes mellitus induced erectile dysfunction; ADSCs, adipose derived stem cells; iNOS, 2 inducible nitric oxide synthase; MAP, mean arterial pressure. ${ }^{*} P<0.05 v s$. control group. Data expressed as 3 mean \pm standard deviation. 